\title{
Where are all the males? Gender-specific typologies of childhood adversity based on a large community sample
}

McAnee, G., Shevlin, M., Murphy, J., \& Houston, JE. (2019). Where are all the males? Gender-specific typologies of childhood adversity based on a large community sample. Child Abuse \& Neglect, 90, 149-159. https://doi.org/10.1016/j.chiabu.2019.02.006

Link to publication record in Ulster University Research Portal

\author{
Published in: \\ Child Abuse \& Neglect
}

Publication Status:

Published (in print/issue): 01/04/2019

DOI:

10.1016/j.chiabu.2019.02.006

\section{Document Version}

Author Accepted version

\section{General rights}

Copyright for the publications made accessible via Ulster University's Research Portal is retained by the author(s) and / or other copyright owners and it is a condition of accessing these publications that users recognise and abide by the legal requirements associated with these rights.

\section{Take down policy}

The Research Portal is Ulster University's institutional repository that provides access to Ulster's research outputs. Every effort has been made to ensure that content in the Research Portal does not infringe any person's rights, or applicable UK laws. If you discover content in the Research Portal that you believe breaches copyright or violates any law, please contact pure-support@ulster.ac.uk. 


\title{
Where are all the males? Gender-Specific Typologies of Childhood Adversity Based on a Large Community Sample.
}

\author{
Grainne McAnee ${ }^{a^{*}}$ \\ Mark Shevlin ${ }^{\mathrm{b}}$ \\ Jamie Murphyb \\ James Houston ${ }^{b}$
}

a Bamford Centre for Mental Health and Wellbeing

b School of Psychology

Both at: Ulster University, Northern Ireland, United Kingdom

* Corresponding author: Grainne McAnee, The Bamford Centre, Ulster University, N. Ireland, United Kingdom. Email: g.mcanee@ulster.ac.uk

Acknowledgments: This study was part funded by a PhD a Department of Education and Learning (DEL) Northern Ireland award to the corresponding author. DEL had no further role in producing this paper for publication.

\section{Conflict of interest}

All authors declare they have no conflicts of interest. 


\begin{abstract}
Background: Methodological issues have been identified when quantifying exposure to adversity and abuse. To address a single type may obscure covarying effects. To sum multiple exposures gives equal weight to each. Latent class analysis (LCA) addresses this by identifying homogenous subpopulations. Most studies using LCA have pooled gender data in spite of evidence that the nature and frequency of exposure differs by gender. Males report more interpersonal abuse, females report more of other exposures, particularly sexual. Objective: This study aimed to identify if stratifying data by gender resulted in different profiles of adversity/abuse.

Participants and setting: The National Epidemiologic Survey on Alcohol and Related Conditions (NESARC) wave II, a large community-based survey, nationally representative of the US population.

Method: This study used 14 indicators of childhood adversity as the basis for LCA.

Results: The number and nature of classes differed by gender. The best solution for females was 4-class: a low risk class; a class at higher risk of sexual abuse; a class at higher risk of physical abuse; a class at higher risk of combined physical and sexual abuse. The best solution for males had only 3-classes; a low risk class, a class at higher risk of sexual abuse; a class at higher risk of physical abuse. The combined dataset resulted in a solution similar to the female solution.

Conclusion: The importance of developing models for males and females separately was evidenced by the male and female classes being differentially associated with mental health variables.
\end{abstract}

Keywords: Adversity, Abuse, Latent Class Analysis, Gender, Childhood Trauma 


\section{Introduction}

Interest in the role of adversity and abuse in psychopathology has expanded beyond the firmly established links between these experiences of adversity and PTSD (Cloitre et al., 2009). Current areas of study are the links with anxiety (Hovens et al., 2010), depression (Kessler, Davis, \& Kendler, 1997), psychosis (Duhig et al., 2015), bipolar disorder (Etain et al., 2013) and substance disorder (Kendler et al., 2000). There are well documented differences in exposure for males and females with males reporting higher overall levels of adversity/abuse, attributable to high levels of interpersonal violence (Kessler et al., 1997; Pink, 2009). Although males report significant levels of sexual abuse, in comparison to overall levels of sexual abuse reported by females, these tend to be relatively lower (Finkelhor \& Dziuba-Leatherman, 1994; Pereda, Guilera, Forns, \& Gomez-Benito, 2009; Perez-Fuentes et al., 2013).

To focus on childhood experiences, child maltreatment may occur in a number of different ways. Butchart, Putney, Furniss, and Kahane (2006) define child maltreatment as,

'all forms of physical and/emotional ill-treatment, sexual abuse, neglect or negligent treatment or commercial or other exploitation, resulting in actual or potential harm to the child's health, survival, development or dignity, in the context of a relationship of responsibility, trust or power' (p.9).

There are a range of abuses contained within child maltreatment (DCSF, 2010). Physical abuse is defined as acts such as hitting, kicking, biting or any other acts of aggression which are likely to hurt or cause significant harm to a child. Sexual abuse includes forcing or enticing a child to take part in sexual activities. These activities may or may not include 
physical contact and they may or may not include penetration. Emotional abuse is considered to be present to some level in all abuses or it may stand alone. It involves persistent emotional maltreatment which results in severe and persistent adverse effects in terms of emotional development. It includes any act which results in a child feeling worthless, unloved, inadequate or only of worth in meeting the needs of another person. Neglect involves failure to meet the basic physical or developmental needs of a child having a detrimental impact on the development or safety of a child. Neglect is expressed developmentally to allow differentiation between the needs of younger and older children.

Early studies addressed either sexual or physical abuse in isolation (Pereda et al., 2009). This was problematic as abuses do not occur in isolation but co-occur (Finkelhor, Ormrod, \& Turner, 2007; Finkelhor, Ormrod, \& Turner, 2009). The work of Finkelhor and colleagues was important in developing the phenomenon of poly-victimisation. A 2007 study which used a nationally representative US sample of 2,030 children was comprised of children from age 2 to age 17 . Results showed that $22 \%$ of the sample had experienced four or more kinds of exposure over one year. These children were classified as poly-victims and they showed more symptoms of trauma than those who were not poly-victims. The effects of this polyvictimisation substantially reduced or eliminated the effects, in terms of trauma symptoms, of experiencing 1-3 different types of abuse and of multiple experiences of a single type of abuse. A 2009 study developed this work further as weighting was applied to different types of abuse. This study also utilised a nationally representative US sample of 1467 children from age 2 to age 17. The study was conducted in two waves and compared results between past year experience of abuse and lifetime experience. Categories were created based on 33 different types of victimisation. The categories were, any maltreatment, sexual victimisation, sexual assault, physical assault, property victimisation and witnessed/indirect victimisation. 
Whilst a weighting was applied, the study concluded that it made little difference to results. The weighting was based on results of regression modelling between the abuse categories and trauma symptoms while controlling for a range of demographics and other abuses. The study again showed that importance of the role of poly-victimisation in reducing or eliminating the effects of single types of abuse. Although findings did not reflect the important difference in weighting of abuses, it did point to patterns of occurrence and cooccurrence of abuse and how understanding these may increase understanding of the impact of abuse on traumatic symptomology.

Mixture models such as latent class analysis (LCA) have been proposed to allow these patterns to be studied. LCA uses observed categorical data, in this case experiences of categories of adversity/abuse. Based on these categories, using maximum likelihood estimates, it divides participants into mutually exclusive and exhaustive latent classes of people who follow a similar pattern of experiences. These can then be used to predict outcomes such as experiencing mental health conditions, in this case, depression, anxiety or PTSD. Multiple models are generated based on 1,2,3,4,5, or 6 mutually exclusive latent classes of people. The model which best describes the data is selected by examining a range of fit statistics as described in the methods section. A 2017 meta-analysis concluded that the use of LCA helps increase understanding of trauma by looking for patterns across different exposures to adversity or abuse. O'Donnell et al. (2017) conducted a systematic review of trauma literature using LCA which was aimed at identifying if there are consistent homogenous subgroups of exposed individuals within populations. The review identified 17 studies which met inclusion criteria. A number of consistent findings were identified across the studies. Typically, the number of latent classes which best describes the samples of individuals used is four. There was usually a class of people characterised by higher 
probability of sexual abuse and there usually a class of people characterised by higher probability of interpersonal abuse.

A further aid to understanding these patterns is to include familial factors which can make adversity/abuse more likely to occur. Finkelhor and Dziuba-Leatherman (1994) state that abuse often occurs within dysfunctional family environments which may contain a variety of these risk factors and co-occurring abuses. There are a wide range of individual, family, social and cultural factors involved (Brown, Cohen, Johnson, \& Salzinger, 1998). Finkelhor et al. (2009) point to types of family constellations that increase risk for victimisation. One such factor in these constellations is parental psychopathology (Copeland, Shanahan, Costell, \& Angold, 2009; Menard, Bandeen-Roche, \& Chilcoat, 2004). Children of parents who are experiencing psychopathology are at increased risk of a range of behavioural, emotional and social difficulties (Leverton, 2003; Vostanis, et al., 2006). Families which are characterised by chaos, multiple or ongoing problems can mean that children are poorly supervised or exposed to risk of victimisation (Menard et al., 2004). Issues such as lack of adequate support, care provision and access to services contribute to this constellation of risk (Östman \& Hansson, 2002). Once a pattern of victimisation is established, this pattern can continue into adulthood.

Gender has been incorporated in one of two ways in LCA studies. First, it has been controlled for as a covariate. Those who controlled for gender include a study by McChesney, Adamson and Shevlin (2015) who used a sample of 10,123 US adolescents to identify 4 classes of adversity including a class characterised by high risk of sexual assault which was associated with being female. Armour, Elkit and Christofferson (2014), used a general population sample of 2980 24-year olds to identify 4 classes again of people, one of these being a class 
associated females that was more likely to experience sexual abuse. Nooner, et al. (2011) used a high-risk sample of 795 11-13 years old US adolescents. This study identified 4 classes, none of which were associated with gender although this study was comprised of a much smaller sample size than previous studies cited.

Second, analysis has been performed on a single gender. Studies who have conducted analysis on a single gender include a study by Shevlin et al., (2013) in which female data only were analysed. This study addressed patterns of lifetime female victimisation using the UK Adult Psychiatric Morbidity Survey. Four classes were identified: a class at high risk of multiple adversity; a class at no risk; a class characterised by high risk of sexual abuse and a class characterised by no risk of sexual abuse.

Although research indicates that profiles will not be shared across gender, no studies were identified that examined if stratification of data by gender would lead to different profiles of adversity/abuse. The current study aimed to address that gap. A large dataset was required to allow this stratification whilst retaining the power needed to effectively implement LCA. A general population dataset allowed for optimum generalisation as opposed to the high-risk population used in many of the studies addressed. Use of LCA addressed poly-victimisation. This study expanded beyond experiences of adversity/abuse into familial context by including a measure of parental psychopathology.

First, this study examined if there was significant heterogeneity in the population in terms of adversity and parental psychopathology. It addressed if these classes differed quantitatively and qualitatively. Second, it stratified the data by gender and re-examined patterns of heterogeneity. Given the relevance of sexual abuse for females, there was an expectation that 
a class of higher probability of experiencing sexual abuse would emerge. Third, this study looked at implications of gender differences. It was expected that the relationship males had with the psychological variables may be moderated by gender. It addressed this by exploring the relationship between classes and a diagnosis of anxiety, depression or PTSD.

\section{Method}

Sample

Analysis was conducted on the second wave of the National Epidemiologic Survey on Alcohol and Related Conditions (NESARC) (Grant \& Dawson, 2006). The NESARC is a longitudinal survey that was designed to be representative of the civilian, noninstitutionalized adult population of the United States (Grant \& Dawson, 2006). Descriptions of the survey design, and data collection processes are available in greater detail elsewhere (Grant, et al., 2003; Grant \& Dawson, 2006; Grant, Kaplan, Moore, \& Kimball, 2007; Grant, Kaplan, Shepard, \& Moore, 2003; Stinson, et al. 2005) but will be summarized here.

Wave 1 of the NESARC was conducted between 2001 and 2002, while Wave II took place between 2004 and 2005. Respondents included those living in private households, boarding or rooming houses, nontransient hotels and motels, shelters, facilities for housing workers, college quarters, group homes, and military personnel living off base (Grant \& Dawson, 2006). One adult was randomly selected from each dwelling. Potential respondents were informed in writing of the nature of the study, the confidentiality procedures that were in place, the intended use for the data and the voluntary nature of their participation (Grant \& Dawson, 2006). Face-to-face, computer-assisted personal interviews were conducted by trained laypersons (Grant \& Dawson, 2006). In Wave 1, 43093 adults were interviewed (81\% response rate). In Wave II, 34653 available respondents (i.e., those who were not deceased, deported, on active military duty, or mentally or physically impaired throughout the follow- 
up period) were reinterviewed ( $86.7 \%$ response rate). The cumulative response rate for both waves combined was $70.2 \%$. Blacks, Hispanics and young adults aged 18-24 years were oversampled in both waves of the NESARC. As such, data were weighted to adjust for this oversampling. In order to be representative of the US population the data was also adjusted for region, age, sex, race, and ethnicity, based on the 2000 Decennial Census (Grant \& Dawson, 2006). The sample for the study was composed of 14564 (42\%) males and 20089 (58\%) females. Age ranged from 20 to 90 years old. There was a significant difference in mean ages for males $(M=48.46, S D=16.76)$ and females $(M=49.49, S D=17.67) ; t$ $(32295)=-5.55, \mathrm{p}<.05$. It is worthy of note at this point that the use of such a large dataset will mean that minor numerical differences, such as those in gender ages will reach statistical significance.

\section{Measures}

Section 13 of the Wave II NESARC survey contained a range of 14 questions about childhood adversity and abuse upon which six categories were based; neglect ( 3 items); childhood physical abuse (CPA) (2 items); witnessing interpersonal violence (IPV) (4 items); molestation (2 items); childhood sexual abuse (CSA) (2 items) and having a parent with mental health issues (1 item). The separation of molestation and sexual abuse was based on abuse through touch versus attempts at or actual penetration. These are both forms of sexual abuse and were separated to analyse if different rates of experience of these abuses occur and if these affect classes produced by LCA by gender. All items are shown in Table 1 along with the rates of each item experienced by gender. Section 16 of wave II contained diagnostic variables for depression, generalised anxiety disorder and PTSD based on DSM IV diagnoses (APA, 2000). 
Analysis

Analyses were conducted in two linked phases. First, LCA analyses were done for the total data, for the male data, and for the female data in relation to the adversities. The 14 childhood items were answered on a 5-point Likert-type scale ('never', (0), 'almost never' (1), ‘sometimes' (2), 'fairly often' (3) and 'very often' (4)). If a respondent answered 'sometimes', 'fairly often', or 'very often' to any of the questions in a category then the category level score was increased by 1 . Table 2 contains the binary categories along with the rate of each item experienced by gender.

Mplus Version 7 (Muthen \& Muthen, 2012) was used to perform LCA using the 6 childhood adversity categories. LCA is a statistical method used to identify homogeneous groups, or classes, from categorical multivariate data. The fit of six models (a 1-class model through to a 6-class model) was assessed. The models were estimated using robust maximum likelihood (Yuan \& Bentler, 2000). To avoid solutions based on local maxima, 500 random sets of starting values were used initially and 100 final stage optimisations. The relative fit of the models was compared by using three information theory-based fit statistics: the Akaike Information Criterion (AIC) (Akaike, 1987), the Bayesian Information Criterion (BIC) (Schwartz, 1978) and the sample size-adjusted Bayesian Information Criterion (ssaBIC) (Schwartz, 1978). The model that produces the lowest values can be judged as the best model. In addition, the Lo-Mendell Rubin (Lo, Mendell, \& Rubin, 2001) adjusted likelihood ratio test (LRT) was used to compare models with increasing numbers of latent classes. When a non-significant value ( $p>0.05$ ) occurs, this suggests that the model with one less class should be accepted. Analysis was performed on the total data, then the male and female data separately. All analyses were conducted using the appropriate weighting variable. 
Second, three binary logistic regression models were specified using hierarchical binary logistic regression in SPSS 23.0. Three categorical variables were created which represented most likely class membership for males, females and the total sample. These were then dummy coded and used as the independent variable in the regression models. The dependent variable for each model, was in turn the diagnosis of anxiety, depression and finally PTSD (0 = no diagnosis; 1 = lifetime diagnosis) taken from NESARC Wave II, section 16.

\section{Results}

The frequencies of experiences of abuse and adversity at the item level as well as chi-square tests to determine if rates of experience differed significantly by gender, are presented in Table 1. Comparing gender experiences, in all except one question, females experienced the adversities/abuses in higher percentages than males. The same two abuse items were experienced in the largest frequencies by both males and females, "How often did a parent or other adult living in your home push, grab, shove, slap or hit you?" (males 17.3\%, females, $15.8 \%$ ), and "How often did a parent or other adult living in your home hit you so hard you had marks or bruises or were injured?" (males $6.7 \%$, females $7.5 \%$ ). The main driver for males experiencing higher levels of abuse was 1 item in the physical abuse category. The largest differences in abuse were for the items related to molestation and sexual abuse with the largest difference being for the item, "How often did an adult or other person touch or fondle you in a sexual way when you didn't want them to or you were too young to know what was happening?" (males 1.3\%, females 6.5\%). The lowest abuse items experienced for

males were jointly, "How often did a parent or other adult living in your home ignore or fail to get you medical treatment when you were sick or hurt?", and "How often did an adult or other person actually have sexual intercourse with you when you didn't want them to or you were too young to know what was happening?" $(0.7 \%)$. For females, the abuse item least 
experienced was, "How often did your father repeatedly hit your mother for at least a few minutes." $(2.0 \%)$.

The frequencies of experience of adversities and abuses at the category level are shown in Table 2. In all cases except for physical abuse (males $18 \%$, females $16.5 \%$ ), females said they had experienced them in higher rates. The biggest gender differences at this overall level were again for molestation (males $1.5 \%$, females $6.7 \%$ ) and sexual abuse (males $1 \%$, females $3.9 \%)$

* table 1 near here

*table 2 near here

The fit indices for males from the LCA are reported in Table 3. For males the 3-class solution was the best model. The AIC, BIC and ssa-BIC were lower for the 3-class solution compared to the 2-class solution and the BIC was also lower for the 3-class than the 4-class solution. In addition, the Lo-Mendell-Rubin's LRT indicated that the 4-class solution is not significantly better than the 3-class solution therefore on the basis of parsimony, the 3-class solution is preferred.

*table 3 near here

The latent class profile plot for males is shown in Figure 1. The largest class was the 'baseline' class ( $\mathrm{N}=13299$ : 89.9\%). This class was characterised by low likelihood of having experienced any of the adversities. The 'sexual abuse' class was the smallest class $(\mathrm{N}=117$ : $0.7 \%$ ) and was characterised by a relatively high probability of endorsing the items related to sexual abuse. The 'physical abuse' class was of intermediate size in relation to the other two $(\mathrm{N}=1061: 9.4 \%)$ and was characterised by a high probability of having experienced physical abuse. 
*Figure 1 near here

The fit indices for females from the LCA are reported in Table 4. For females the 4-class solution was the best model. The AIC, BIC and ssa-BIC were lower for the 4-class solution compared to the 3-class and 2-class solutions. The BIC and the ssa-BIC were also lower for the 4-class solution compared to the 5-class solution. The Lo-Mendell-Rubin's LRT indicates that the 5-class solution is not significantly better than the 4-class solution therefore on the basis of parsimony, the 4-class solution is preferred.

*table 4 near here

The latent class profile plot for females is shown in Figure 2. The largest class was the baseline class ( $\mathrm{N}=17090: 84.2 \%)$. This class was characterised by low likelihood of having experienced any of the adversities or abuses. The 'physical and sexual abuse' was the smallest class, $(\mathrm{N}=405: 2.0 \%)$. It was characterised by a relatively high probability of endorsing the items related to both physical and sexual abuse. Two intermediate classes emerged. The 'physical abuse' class $(\mathrm{N}=1576,10.0 \%)$ and the 'sexual abuse' class $(\mathrm{N}=903$, $3.8 \%)$.

*figure 2 near here

The fit indices for the total data from the LCA are reported in Table 5. For the total data, the 4-class solution was the best model. The AIC, BIC and ssa-BIC were lower for the 4-class solution compared to the 3-class and 2-class solutions. The BIC and the ssa-BIC were also lower for the 4-class solution compared to the 5-class solution. The Lo-Mendell-Rubin's LRT indicates that the 5-class solution is not significantly better than the 4-class solution therefore on the basis of parsimony, the 4-class solution is preferred.

*table 5 near here 
The latent class profile plot for the total data is shown in Figure 3. Class patterns reflected those for the female data. The 'baseline' class, was the largest $(\mathrm{N}=29885: 86.8 \%)$. This class was characterised by low likelihood of having experienced any of the abuses/adversities. The 'physical and sexual abuse' class was the smallest class ( $\mathrm{N}=454: 1.3 \%)$. Two intermediate classes also emerged. The 'sexual abuse' class $(\mathrm{N}=835,2.4 \%)$ and the 'physical abuse' class $(\mathrm{N}=3278,9.5 \%)$.

*figure 3 near here

*Table 6 near here

Three categorical variables were created, based on most likely class membership for males, females and the total sample. Three separate binary logistical regression models were created where class membership was dummy coded and used as the independent variable and lifetime diagnosis of anxiety, depression and PTSD were used as the dependent variables. Table 6 shows the results from the binary logistic regressions. To focus on gender differences, the main difference can be seen when addressing the results for those in the 'sexual abuse' class. In relation to a lifetime diagnosis of anxiety, males in the 'sexual abuse' class were 2.1 times more likely to be diagnosed than females. The same pattern is seen for this 'sexual abuse' class in relationship to both depression and PTSD. Males in the 'sexual abuse' class are 1.8 times more likely to be diagnosed with depression than females in the 'sexual abuse' class. Males in the 'sexual abuse' class are 1.5 times more likely to be diagnosed with PTSD than females. If the data was not stratified and the total data finding was used to analyse this relationship, it would reflect the female data findings and obscure the higher odds ratios (OR) for males in every case. 


\section{Discussion}

Although research indicates that profiles will not be shared across gender, no studies were identified that examined if stratification of data by gender would lead to different profiles of adversity and abuse. The current study aimed to address that gap. First, this study examined if there was significant heterogeneity in the NESARC sample in terms of adversity, abuse and parental psychopathology. It addressed if these classes differed quantitatively and qualitatively. Second, it stratified the data by gender and re-examined patterns of heterogeneity. Given the relevance of sexual abuse for females, there was an expectation that a class of higher probability of experiencing sexual abuse would emerge. Third, this study looked at implications of gender differences: it was expected that the relationship males had with the psychological variables underpinning the study might differ from the relationship between females and the same variables. It addressed this by estimating the association between classes and a diagnosis of anxiety, depression or PTSD.

The major findings of the study where firstly that there were classes of people who grouped together in the data in terms of their shared patterns of experiences of abuse and adversity. Secondly, that stratifying the data by gender did in fact produce classes of people that differed both quantitatively and qualitatively. Thirdly the study did show that there were markedly different outcomes in relation to the mental health variables used for males who had experienced sexual abuse. Differences that were obscured in analysis which did not separate by gender. This discussion will explore the results for experiences of adversity as represented by responses to the survey questions. It will then address the main findings in turn. The findings show that although any experiences of abuse and adversity are unacceptable, they are not the experience of the vast majority of the population. 
In terms of gender there were differences in experiences of adversity/abuse when addressing the categories that were created from the answers to the individual questions (Table 2). These were consistent with previous literature. These findings showed that males and females differ in the frequency and type of exposure they experience. Physical abuse was the most commonly reported at an overall level (17.2\%) and also for males (18\%) in line with existing literature (Kessler et al., 1997). For females, while overall levels of abuse reported were lower due to the high level of interpersonal violence reported, reports of all other types of adversity, in particular sexual, were higher than for males, again in line with existing literature (Pereda et al., 2009; Perez-Fuentes et al., 2013). Kessler et al. (1997) reported on experiences of childhood abuse in an analysis of the US National Comorbidity Study. Results around physical and sexual abuse showed parallels with findings of the current study. The pattern of higher experiences by males of interpersonal physical violence was evidenced by the rates of experience of aggression by a male parent of $24.3 \%$ and by a female parent of $15.1 \%$. Female experience of aggression by a male parent was only $16.2 \%$ with a slightly higher rate of $17.6 \%$ for rates of aggression by a female parent. The current study did not differentiate between parental gender when reporting rates of physical abuse by a parent (Male $=18 \%$, female $=16.5 \%)$. For sexual abuse, the current study separated molestation $($ Male $=1.5 \%$, Female $=6.7 \%)$ and sexual abuse $($ Male=1.0\%, Female=3.9\% $)$. Kessler et al. (1997) further differentiated with four categories: isolated molestation (Male=1.3\%, Female $=5.1 \%)$, repeated molestation $($ Male $=1.2 \%$, Female $=6.1 \%)$, isolated rape $($ Male $=0.3 \%$, Female $=3.4 \%)$ and repeated rape $($ Male $=0.2 \%$, Female $=1.8 \%)$. Although total rates of experiences of these abuses vary across studies depending on how questions are structured, these patterns between genders remain consistent with the relative differences between them being a constant feature. These patterns, consistent across population-based studies, suggested that different profiles may be evident for males and females. 
Major findings which centred on the classes of people who emerged from the LCA are now examined. A point to note is that results from the LCA show that probability of abuse or adversity is low for the vast majority of the population. The baseline class for each set of data - total, male and female, is the largest by far. For the total data, the baseline class represents $86.8 \%$ of the sample. For the male data, the baseline class represents $89.9 \%$ of the sample. For the female data, the baseline class represents $84.2 \%$ of the sample. There were, as expected groups of people who shared patterns of abuse across the categories, reflecting findings of the 17 studies identified and included in 2017 meta-analysis (O'Donnell et al.).

To address the main objective of the study, results from the LCA showed that as well as different profiles emerging from the dataset as a whole, there were different profiles for males and females. The best model for males was represented by three groups of people (Table 3). The best model for females was represented by four groups (Table 4). The best model for the total data was the same as the female solution in that it was represented by four distinct groups of people (Table 5). More classes were required to explain the occurrence and co-occurrence of abuse and adversity for females, reflecting the total data. It seems the more complex patterns of occurrence and co-occurrence for females tend to be what is represented in the total sample rather than the male patterns. Results for males are therefore obscured if the data is not separated by gender.

As well as the main difference of the number of classes, the nature of the groups of people also differed. For the male data (Figure 1), differences were qualitative. The baseline class showed no resemblance to the other two classes. The sexual abuse and physical abuse classes had a similar pattern over neglect, physical abuse and witnessing IPV, although the probabilities were much higher across these for those in the physical abuse class. The pattern 
however across sexual abuse and molestation was completely different and were practically a mirror image of each other. In terms of parental psychopathology, this had more effect for the class of males who were more likely to experience physical abuse than for the sexual abuse class. For females (Figure 2) there were classes which differed qualitatively but also classes that differed quantitatively with both each other and with the male classes. Although they had a similar pattern across neglect, physical abuse and witnessing IPV, with males reporting in higher numbers across these, and although they both had that higher probability for molestation, for males the probability was higher and was consistently higher for sexual abuse while for the female class, that was not the case. The physical abuse classes were similar across gender both quantitatively and qualitatively. The issue of parental psychopathology reflected the male data in that it was more relevant for those in the physical abuse than the sexual abuse class, with the highest likelihood being for those in the combined physical and sexual abuse class. The total data (Figure 3) reflected the female data.

A discussion in the context of the systematic review done by O'Donnell et al. (2017) highlights the methodological issues that are apparent when trying to compare all studies of abuse, adversity and trauma. Of the 17 studies included in the review there were differences in type of sample, size of sample, aspects of abuse addressed, number of items underlying the measures used and analysis done. There were however some areas of commonality. Most of the studies identified a model represented by four groups of people as optimal, in common with both the optimal models for the female data and the total data. The optimal models usually contained both group of people at low risk and a group of people at high risk. Where gender associations were addressed it was usual that females were in the majority if classes were characterised by sexual abuse. The final area in common was that none of the studies were stratified by gender. 
The results of the binary logistical regressions reflect that if the data is not stratified by gender, results that are particularly significant for males will not be seen. Results showed that for the sexual abuse class of males, ORs for anxiety, depression and PTSD were all higher than for females in the corresponding class (Table 6). The male sexual abuse class were 2.1 times more likely to have a diagnosis of anxiety. For all female classes, the ORs were similar to the total sample. The male sexual abuse class were 1.8 times more likely to have a diagnosis of depression. For all female classes, the ORs were similar to the total sample. The male sexual abuse class were 1.5 times more likely to have a diagnosis of PTSD. For all female classes, the ORs were similar to the total sample. In all cases the female and the total sample seem to be similar compared to the male. It appears that if data is not stratified by gender, inferences which are made are about the female data, and important information concerning males is not evident.

The main strengths of this study were that it is the first large scale, national representative model of gender specific abuse and adversity which included broader contextual variables in the form of parental psychopathology. It moved beyond the methodological limitations of studies which do not address poly-victimisation, beyond the limitation of studies which sum adversity and beyond the limitations of studies which do not include family context. It is the first study which addressed gender by stratifying data. Whilst using a large scale epidemiological survey has inherent strengths, there are conversely, a set of accompanying limitations. One of the main limitations centred around the types and definitions of abuse used in the survey. The survey is broad and was not designed primarily to measure experiences of abuse. As a consequence, definitions are practically and conceptually more narrow than other studies which are focused on abuse and its links to psychopathology. For example, NESARC assessed CSA with only four questions compared to the in-depth 
questioning used in other surveys primarily aimed at assessing abuse and neglect. It lacks details on the contexts in which abuse and neglect may have occurred. A significant limitation in this area is the omission of emotional abuse. As studies have increased in sophistication, the inclusion of emotional abuse has become a focus and the significant impact of emotional abuse has become clear. Varese et al. (2012) highlight this issue in a meta-analysis which addressed the links between childhood adversity and risk of psychosis. The meta-analysis showed that ORs were higher for emotional abuse than any of the other included abuses - sexual abuse, physical abuse, neglect, bullying or parental death. Finally, whilst it moves into the area of family context by utilising parental psychopathology, again here the definition and scope of parental psychopathology is narrow in that it requires an indication that parents were treated or hospitalised. Important further work would be to develop this area further in terms of both parental psychopathology and by addressing other factors contributing to these constellations of risk. Other limitations include that measurement utilised a Likert Scale which can lead to subjective interpretation of words such as 'hardly ever'. This study adopted a statistically conservative approach by treating a 'hardly ever' response as a 'no'. The authors accept wholly that even one experience of abuse can leave a profound and lasting effect, and this was not intended to trivialise that. It was intended only to balance the effects of over reporting of less significant events due to the subjective nature of the scale used, such as e.g. someone reporting that they went without a minor item for school. A further limitation is that sexual abuse and molestation are separated in the study in order to address differences in abuse through the use of touch versus, abuse through attempted or actual penetration. This reflects studies such as Kessler et al. (1997) in examining sub-categories of sexual abuse. They are however both types of sexual abuse and could equally have been treated as a single category. The survey did not include some sections of the population such as those under 18 or those in jail or hospitalised at the time of 
the interview (Perez-Fuentes et al., 2013). Lastly, the survey responses were subject to the possibility of recall bias as respondents were asked to report on lifetime events of adversity/abuse. Research has however suggested that such reports are surprisingly reliable (Read, van Os, Morrison, \& Ross, 2005).

In addressing the main objective of this study, it is clear that research to date using LCA to model population data may have been reporting findings based solely on the female data in the sample. Important findings for males who have been sexually abuse may have been missed. Combined with this is the importance of including family level contextual information to allow this work to continue to expand and develop in sophistication. Incorporating both these findings may advance our understanding of the complex and multifaceted relationship between abuse and adversity and clinical outcomes. This study shows that for boys who are sexually abused, the risk of depression and anxiety is much greater and this needs to be the impetus to explore this issue further. 


\section{References}

Akaike, H. (1987). Factor-analysis and AIC. Psychometrika, 52, 317-332.

American Psychiatric Association. (2000). Diagnostic and statistical manual of mental disorders. Text revision (4th ed., rev. ed.). Washington, DC: Author.

Armour, C., Elklit, A., \& Christoffersen, M. N. (2014). A latent class analysis of childhood maltreatment: Identifying abuse typologies. Journal of Loss and Trauma, 19, 23-39.

Butchart, A., Putney, H., Furniss, T., and Kahane, T. (2006). Preventing Child

Maltreatment: a Guide to Taking Action and Generating Evidence. Geneva: World Health Organisation.

Brown, J., Cohen, P., Johnson, J.G., \& Salzinger, S. (1998). A longitudinal analysis of risk factors for child maltreatment: findings of a 17-year prospective study of officially recorded and self-reported child abuse and neglect. Child Abuse and Neglect, 22, 1065-1078.

Cloitre, M., Stolbach, B. C., Herman, J. L., Kolk, B. V. D., Pynoos, R., Wang, J., \& Petkova, E. (2009). A developmental approach to complex PTSD: Childhood and adult cumulative trauma as predictors of symptom complexity. Journal of Traumatic Stress, 22, 399-408.

Copeland, W., Shanahan, L., Costell, J., \& Angold, A. (2009). Configurations of common childhood psychosocial risk factors. Journal of Child Psychology and Psychiatry, 50, 451-459.

Department for Children, School and Families (2010) Working Together to Safeguard Children: Government response to public consultation, Chapter 8, Serious Case Reviews. London: DCSF.

Duhig, M., Patterson, S., Connell, M., Foley, S., Capra, C., Dark, F., .. \& Scott, J. (2015). 
The prevalence and correlates of childhood trauma in patients with early psychosis. Australian \& New Zealand Journal of Psychiatry, 49, 651-659.

Etain, B., Aas, M., Andreassen, O. A., Lorentzen, S., Dieset, I., Gard, S., ... \& Henry, C. (2013). Childhood trauma is associated with severe clinical characteristics of bipolar disorders. The Journal of Clinical Psychiatry, 74, 991-998.

Finkelhor, D., \& Dziuba-Leatherman, J. (1994). Children as victims of violence: a national survey. Paediatrics, 94, 413-420.

Finkelhor, D., Ormrod, R. K., \& Turner, H. (2007). Poly-victimisation: a neglected component in child victimisation. Child Abuse and Neglect, 31, 7-26.

Finkelhor, D., Ormrod, R. K., \& Turner, H. (2009). Lifetime assessment of poly victimisation in a national sample of children and youth. Child Abuse and Neglect, 33, 403-411.

Grant, B. F., \& Dawson, D. A. (2006). Introduction to the national epidemiologic survey on alcohol and related conditions. Alcohol Research, 29, 74.

Grant, B. F., Dawson, D. A., Stinson, F. S., Chou, P. S., Kay, W., \& Pickering, R. (2003). The Alcohol Use Disorder and Associated Disabilities Interview Schedule-IV (AUDADIS-IV): reliability of alcohol consumption, tobacco use, family history of depression and psychiatric diagnostic modules in a general population sample. Drug and Alcohol Dependence, 71, 7-16.

Grant, B. F., Kaplan, K., Moore, T., \& Kimball, J. (2007). 2004-2005 Wave 2 National Epidemiologic Survey on Alcohol and Related Conditions: Source and Accuracy Statement. Bethesda, MD: National Institute on Alcohol Abuse and Alcoholism.

Grant, B. F., Kaplan, K., Shepard, J., \& Moore, T. (2003). Source and accuracy statement for wave 1 of the 2001-2002 National Epidemiologic Survey on Alcohol and Related Conditions. Bethesda, MD: National Institute on Alcohol Abuse and Alcoholism. 
Hovens, J. G., Wiersma, J. E., Giltay, E. J., Van Oppen, P., Spinhoven, P., Penninx, B. W., \& Zitman, F. G. (2010). Childhood life events and childhood trauma in adult patients with depressive, anxiety and comorbid disorders vs. controls. Acta Psychiatrica Scandinavica, 122, 66-74.

Kendler, K. S., Bulik, C. M., Silberg, J., Hettema, J. M., Myers, J., \& Prescott, C. A. (2000). Childhood sexual abuse and adult psychiatric and substance use disorders in women: an epidemiological and cotwin control analysis. Archives of General Psychiatry, 57, 953-959.

Kessler, R. C., Davis, C. G., \& Kendler, K. S. (1997). Childhood adversity and adult psychiatric disorder in the US National Comorbidity Survey. Psychological Medicine, 27, 1101-1119.

Leverton, T. J. (2003). Parental psychiatric illness: the implications for children. Current opinion in Psychiatry, 16, 395-402.

Lo, Y., Mendell, N. R., \& Rubin, D. B. (2001). Testing the number of components in a normal mixture. Biomentrika, 88, 767-778.

McChesney, G. C., Adamson, G., \& Shevlin, M. (2015). A latent class analysis of trauma based on a nationally representative sample of US adolescents. Social Psychiatry and Psychiatric Epidemiology, 50, 1207-1217.

Menard, C. B., Bandeen-Roche, K. J., \& Chilcoat, H. D. (2004). Epidemiology of multiple childhood traumatic events: child abuse, parental psychopathology, and other familylevel stressors. Social Psychiatry and Psychiatric Epidemiology, 39, 857-865.

Muthen, L. K., \& Muthen, B. O. (2012). Mplus User's Guide (7th ed). Los Angeles: California.

Nooner, K., Litrownik, A., Thompson, R., Margolis, B., English, D., Knight, E., 
Everson, M., \& Roesch, S. (2010). Youth self-report of physical and sexual abuse: A latent class analysis. Child Abuse and Neglect, 34, 146-154.

O'Donnell, M. L., Schaefer, I., Varker, T., Kartel, D., Forbes, D., Bryant, R. A., ... \& Felmingham, K. (2017). A systematic review of person-centred approaches to investigating patterns of trauma exposure. Clinical Psychology Review, 57, 208-225.

Östman, M., \& Hansson, L. (2002). Children in families with a severely mentally ill member. Social Psychiatry and Psychiatric Epidemiology, 37, 243-248.

Pereda, N., Guilera, G., Forns, M., \& Gomez-Benito, J. (2009). The prevalence of child sexual abuse in community and student samples: A meta-analysis. Clinical Psychology Review, 29, 328-338.

Perez-Fuentes, G., Olfson, M., Villegas, L., Morcillo, C., Wang, S., \& Blano, C. (2013). Prevalence and correlates of child sexual abuse: a national study. Comprehensive Psychiatry, 54, 16-27.

Pink, B. (2009). Technical Manual. National Survey of Mental Health and Wellbeing, confidentialised unit record files, Australia 2007. Statistics Commonwealth of Australia, Canberra.

Read, J., Van Os, J., Morrison, A.P., \& Ross, C.A. (2005). Childhood trauma, psychosis and schizophrenia: a literature review with theoretical and clinical implications. Acta Psychiatrica Scandinavica, 112, 330-350.

Schwartz, G. (1978). Estimating the dimension of a model. Annals of Statistics, 6, 461 464.

Shevlin, M., O’Neill, T., Houston, J. E., Read, J., Bentall, R. P., \& Murphy, J. (2013). Patterns of lifetime female victimisation and psychotic experiences: a study based on the UK Adult Psychiatric Morbidity Survey 2007. Social Psychiatry and Psychiatric Epidemiology, 48, 15-24. 
Stinson, F. S., Grant, B. F., Dawson, D. A., Ruan, W. J., Huang, B., \& Saha, T. (2005). Comorbidity between DSM-IV alcohol and specific drug use disorders in the United States: results from the National Epidemiologic Survey on Alcohol and Related Conditions. Drug and Alcohol Dependence, 80, 105-116.

Varese, F., Smeets, F., Drukker, M., Lieverse, R., Lataster, T., Viechtbauer, W., ... \& Bentall, R. P. (2012). Childhood adversities increase the risk of psychosis: a meta-analysis of patient-control, prospective-and cross-sectional cohort studies. Schizophrenia bulletin, $38,661-671$.

Vostanis, P., Graves, A., Meltzer, H., Goodman, R., Jenkins, R., \& Brugha, T. (2006). Relationship between parental psychopathology, parenting strategies and child mental health. Social Psychiatry and Psychiatric Epidemiology, 41, 509-514.

Yuan, K. H., \& Bentler, P. M. (2000). Three likelihood- based methods for mean and covariance structure analysis with nonnormal missing data. Sociological Methodology, 30, 165-200. 
Typologies of childhood adversity/abuse and gender 27

Table 1 Frequencies, Percentages and Chi-Squares for Rates of Experience of Adversity and Abuse by Screening Item - Individual Level.

\begin{tabular}{|c|c|c|c|c|}
\hline Binary variable/screening item & $\begin{array}{l}\text { Male } \\
\text { Yes }(\%)\end{array}$ & $\begin{array}{l}\text { Female } \\
\text { Yes }(\%)\end{array}$ & $\begin{array}{l}\text { Total } \\
\text { Yes }(\%)\end{array}$ & Chi-Square \\
\hline \multicolumn{5}{|l|}{ Neglect } \\
\hline $\begin{array}{l}\text { How often did you go without things you needed like clothes, shoes or } \\
\text { school supplies because a parent or other adult living in your home } \\
\text { spent the money on themselves? }\end{array}$ & $770(4.9)$ & $1356(5.9)$ & $2126(5.5)$ & $\chi^{2}(5, N=34653)=63.115, p<.01$ \\
\hline $\begin{array}{l}\text { How often did a parent or other adult living in your home make you go } \\
\text { hungry or not prepare regular meals? }\end{array}$ & $375(2.6)$ & $707(3.2)$ & $1082(2.8)$ & $\chi^{2}(5, N=34653)=56.691, p<.01$ \\
\hline $\begin{array}{l}\text { How often did a parent or other adult living in your home ignore or fail } \\
\text { to get you medical treatment when you were sick or hurt? }\end{array}$ & $312(0.7)$ & $735(3.4)$ & $1047(2.7)$ & $\chi^{2}(5, N=34653)=70.992, p<.01$ \\
\hline \multicolumn{5}{|l|}{ Physical Abuse } \\
\hline $\begin{array}{l}\text { How often did a parent or other adult living in your home push, grab, } \\
\text { shove, slap or hit you? }\end{array}$ & $2655(17.3)$ & $3112(15.8)$ & $6037(16.5)$ & $\chi^{2}(5, N=34653)=238.032, p<.01$ \\
\hline $\begin{array}{l}\text { How often did a parent or other adult living in your home hit you so } \\
\text { hard you had marks or bruises or were injured? }\end{array}$ & $1066(6.7)$ & $1642(7.5)$ & $2708(7.1)$ & $\chi^{2}(5, N=34653)=120.014, p<.01$ \\
\hline Witnessing IPV & & & & \\
\hline $\begin{array}{l}\text { How often did your father, step-father, foster or adoptive father do } \\
\text { ANY of the following to your mother, step-mother, foster or adoptive } \\
\text { mother? }\end{array}$ & & & & \\
\hline - Push, grab, slap or throw something at her? & $1012(6.5)$ & $2045(9.4)$ & 3057 (14.7) & $\chi^{2}(5, N=34653)=187.064, p<.01$ \\
\hline - Kick, bite, hit her with a fist, or hit her with something hard? & $698(4.3)$ & $1510(6.8)$ & $2280(5.7)$ & $\chi^{2}(5, N=34653)=169.345, p<.01$ \\
\hline - Repeatedly hit her for at least a few minutes? & $465(2.7)$ & $1160(5.1)$ & $1625(4.0)$ & $\chi^{2}(5, N=34653)=160.838, p<.01$ \\
\hline
\end{tabular}


Typologies of childhood adversity/abuse and gender 28

\begin{tabular}{|c|c|c|c|c|}
\hline Binary variable/screening item & $\begin{array}{l}\text { Male } \\
\text { Yes }(\%)\end{array}$ & $\begin{array}{l}\text { Female } \\
\text { Yes }(\%)\end{array}$ & $\begin{array}{l}\text { Total } \\
\text { Yes }(\%)\end{array}$ & Chi-Square \\
\hline $\begin{array}{l}\text { - Threaten her with a knife or gun or use a knife or gun to hurt } \\
\text { her? }\end{array}$ & $168(1.1)$ & $474(2.0)$ & $642(1.6)$ & $\chi^{2}(5, N=34653)=94.151, p<.01$ \\
\hline \multicolumn{5}{|l|}{ Molestation } \\
\hline $\begin{array}{l}\text { How often did an adult or other person touch or fondle you in a sexual } \\
\text { way when you didn't want them to or you were too young to know } \\
\text { what was happening? }\end{array}$ & $208(1.3)$ & $1341(6.5)$ & $1549(4.0)$ & $\chi^{2}(5, N=34653)=809.455, p<.01$ \\
\hline $\begin{array}{l}\text { How often did an adult or other person have you touch their body in a } \\
\text { sexual way when you didn't want them to or you were too young to } \\
\text { know what was happening? }\end{array}$ & $162(1.0)$ & $826(3.9)$ & $988(2.5)$ & $\chi^{2}(5, N=34653)=369.955, p<.01$ \\
\hline Sexual abuse & & & & \\
\hline $\begin{array}{l}\text { How often did an adult or other person attempt to have sexual } \\
\text { intercourse with you when you didn’t want them to or you were too } \\
\text { young to know what was happening? }\end{array}$ & $141(0.9)$ & $820(3.7)$ & $961(2.4)$ & $\chi^{2}(5, N=34653)=465.445, p<.01$ \\
\hline $\begin{array}{l}\text { How often did an adult or other person actually have sexual intercourse } \\
\text { with you when you didn't want them to or you were too young to know } \\
\text { what was happening? }\end{array}$ & $117(0.7)$ & $570(2.4)$ & $687(1.6)$ & $\chi^{2}(5, N=34653)=335.603, p<.01$ \\
\hline Parent with mental health issues & & & & \\
\hline $\begin{array}{l}\text { Before you were } 18 \text { years old, was a parent or other adult living in your } \\
\text { home treated or hospitalised for mental illness? }\end{array}$ & $719(4.9)$ & $1140(5.8)$ & $1859(5.4)$ & $\chi^{2}(2, N=34653)=9.824, p<.01$ \\
\hline
\end{tabular}


Table 2 Frequencies and Percentages of Rates of Experience of Adversity and Abuse - Binary Variable Level.

\begin{tabular}{llllc}
\hline Binary variable & $\begin{array}{c}\text { Male } \\
\text { Yes } \\
(\%)\end{array}$ & $\begin{array}{l}\text { Female } \\
\text { Yes } \\
(\%)\end{array}$ & $\begin{array}{l}\text { Total } \\
\text { Yes } \\
(\%)\end{array}$ & Chi-Square \\
\hline Neglect & 994 & 1723 & 2717 & $\chi^{2}(2, N=34653)=35.861, p<.01$ \\
& $(6.4)$ & $(7.5)$ & $(7.6)$ & \\
Physical Abuse & 2766 & 3528 & 6294 & $\chi^{2}(2, N=34653)=11.707, p<.01$ \\
& $(18.0)$ & $(16.5)$ & $(17.2)$ & \\
Witnessing IPV & 1069 & 2120 & 3189 & $\chi^{2}(2, N=34653)=106.525, p<.01$ \\
& $(6.9)$ & $(9.7)$ & $(8.3)$ & \\
Molestation & 233 & 1390 & 1623 & $\chi^{2}(2, N=34653)=540.719, p<.01$ \\
& $(1.5)$ & $(6.7)$ & $(4.2)$ & \\
Sexual abuse & 166 & 863 & 1029 & $\chi^{2}(2, N=34653)=303.322, p<.01$ \\
& $(1.0)$ & $(3.9)$ & $(2.5)$ & \\
Parent with mental health & 719 & 1140 & 1859 & $\chi^{2}(2, N=34653)=9.824, p<.01$ \\
issues & $(4.9)$ & $(5.8)$ & $(5.4)$ & \\
\hline
\end{tabular}


Table 3 Fit Indices for the Latent Class Analysis of the Adversity/Abuse Variables for Males.

\begin{tabular}{|c|c|c|c|c|c|c|}
\hline $\begin{array}{l}\text { Number of } \\
\text { Classes }\end{array}$ & Loglikelihood & AIC & $\mathrm{BIC}$ & ssa-BIC & LMRA-LRT & P-Value \\
\hline 1 & -18724.080 & 37460.159 & 37505.641 & 37486.574 & & \\
\hline 2 & -17294.062 & 34614.124 & 34712.668 & 34671.356 & 2818.014 & .000 \\
\hline 3 & -17056.375 & 34152.749 & 34304.356 & 34240.797 & 468.391 & .000 \\
\hline 4 & -17026.236 & 34106.471 & 34311.140 & 34225.336 & 59.392 & .151 \\
\hline 5 & -17017.777 & 34103.554 & 34361.285 & 34253.236 & 16.669 & .311 \\
\hline 6 & -17011.692 & 34105.385 & 34416.178 & 34285.883 & 11.991 & .477 \\
\hline
\end{tabular}




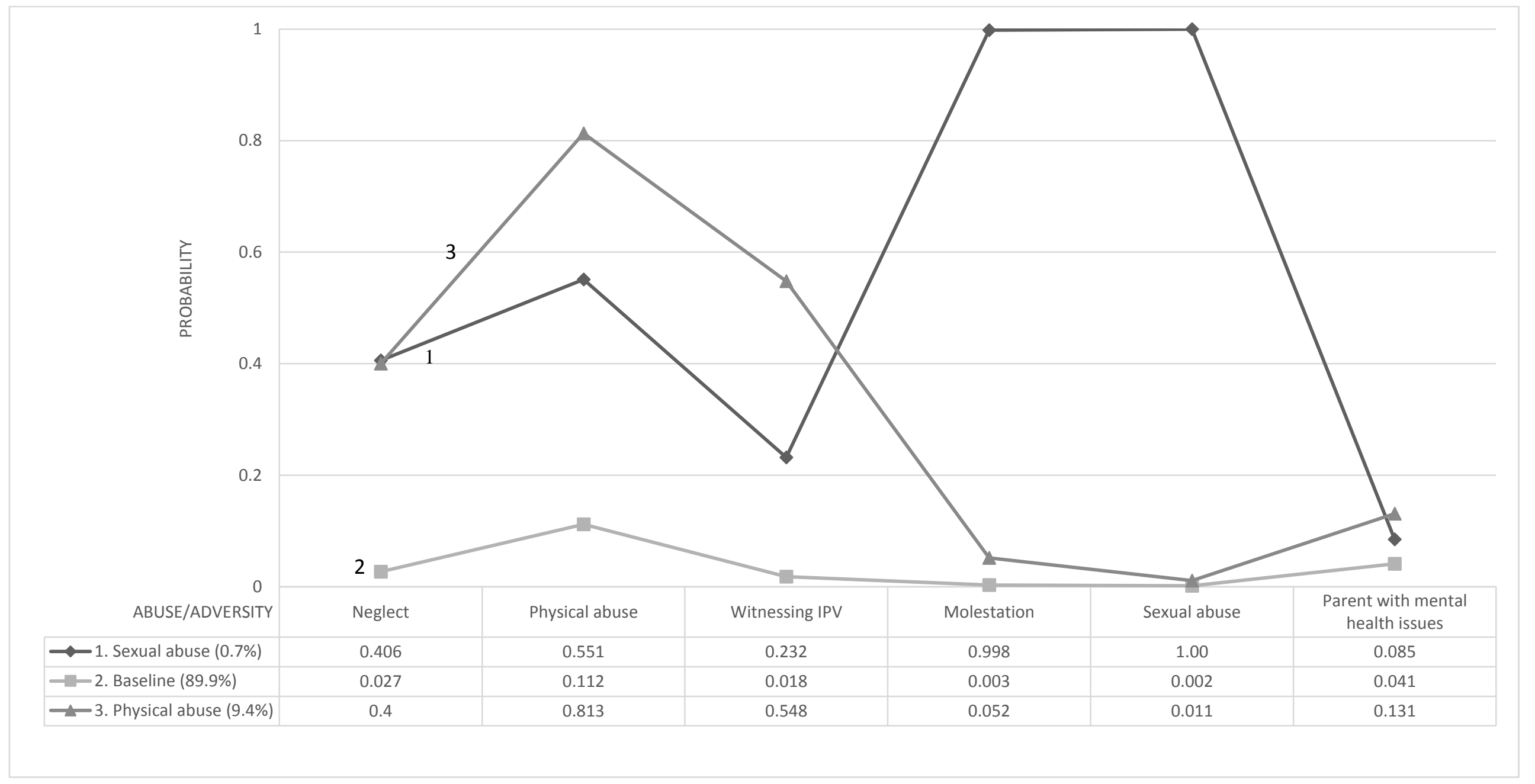

Figure 1 Profile Plot- Latent Class Analysis for Males. 
Table 4 Fit Indices for The Latent Class Analysis of The Adversity/Abuse Variables for Females.

\begin{tabular}{ccccccc}
\hline $\begin{array}{l}\text { Number of } \\
\text { classes }\end{array}$ & Loglikelihood & AIC & BIC & ssa-BIC & $\begin{array}{c}\text { LMRA- } \\
\text { LRT }\end{array}$ & P-Value \\
\hline 1 & -33375.265 & 66762.530 & 66809.944 & 66790.876 & & \\
2 & -29470.919 & 58967.838 & 59070.567 & 59029.254 & 7697.640 & .000 \\
3 & -28763.140 & 57566.280 & 57724.325 & 57660.766 & 1395.427 & .000 \\
4 & -28631.139 & 57316.278 & 57529.638 & 57443.833 & 260.248 & .000 \\
5 & & & & & & \\
& -28614.388 & 57317.499 & 57586.175 & 57478.125 & 12.597 & .480 \\
6 & & & & & & .641
\end{tabular}

$\overline{\mathrm{AIC}}=$ Akaike information criterion, $\mathrm{BIC}=$ Bayesian information criterion, $\mathrm{ssa}-\mathrm{BIC}=$ sample size adjusted BIC, LMRA-LRT = Lo-Mendell-Rubin's adjusted likelihood ratio test. 


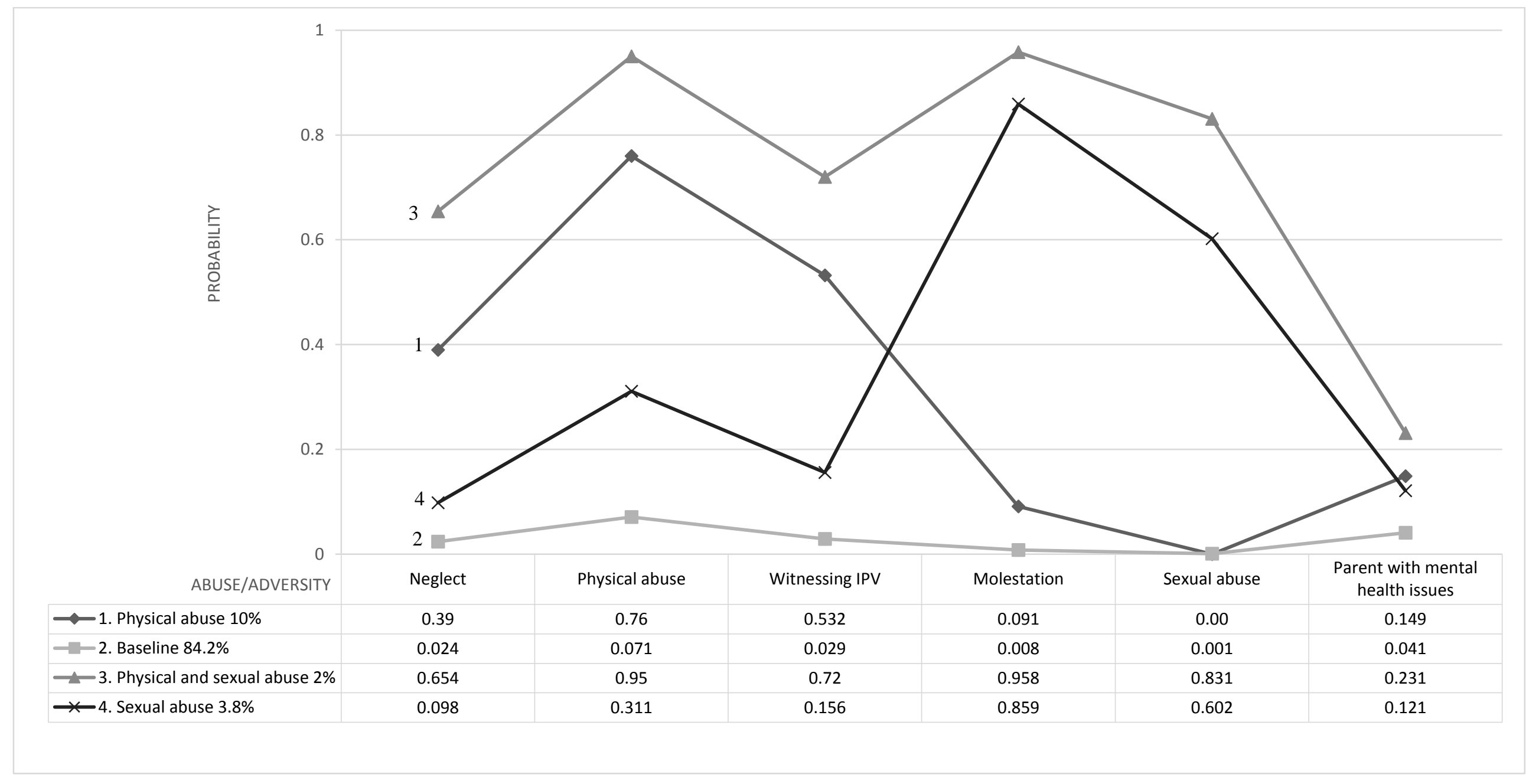

Figure 2 Profile Plot - Latent Class Analysis for Females. 
Table 5 Fit Indices for the Latent Class Analysis of the Adversity/Abuse Variables for Total Data.

\begin{tabular}{ccccccc}
\hline $\begin{array}{l}\text { Number of } \\
\text { classes }\end{array}$ & Loglikelihood & AIC & BIC & ssa-BIC & $\begin{array}{c}\text { LMRA- } \\
\text { LRT }\end{array}$ & $\begin{array}{c}\text { P- } \\
\text { Value }\end{array}$ \\
\hline 1 & -51879.217 & 103770.435 & 103821.118 & 103802.050 & & \\
2 & -46722.552 & 93471.105 & 93580.920 & 93539.606 & 10174.207 & .000 \\
3 & -45709.229 & 91458.459 & 91627.405 & 91563.845 & 1999.308 & .000 \\
4 & -45560.882 & 91175.764 & 91403.842 & 91318.036 & 292.62 & .000 \\
& & & & & & \\
5 & -45553.742 & 91175.484 & 91462.693 & 91354.641 & 14.088 & .488 \\
6 & & & & & & \\
& -45545.881 & 91173.762 & 91520.103 & 91389.805 & 14.411 & .551
\end{tabular}

AIC $=$ Akaike information criterion, $\mathrm{BIC}=$ Bayesian information criterion, ssa-BIC $=$ sample size adjusted BIC, LMRA-LRT $=$ Lo-Mendell-Rubin's adjusted likelihood ratio test. 


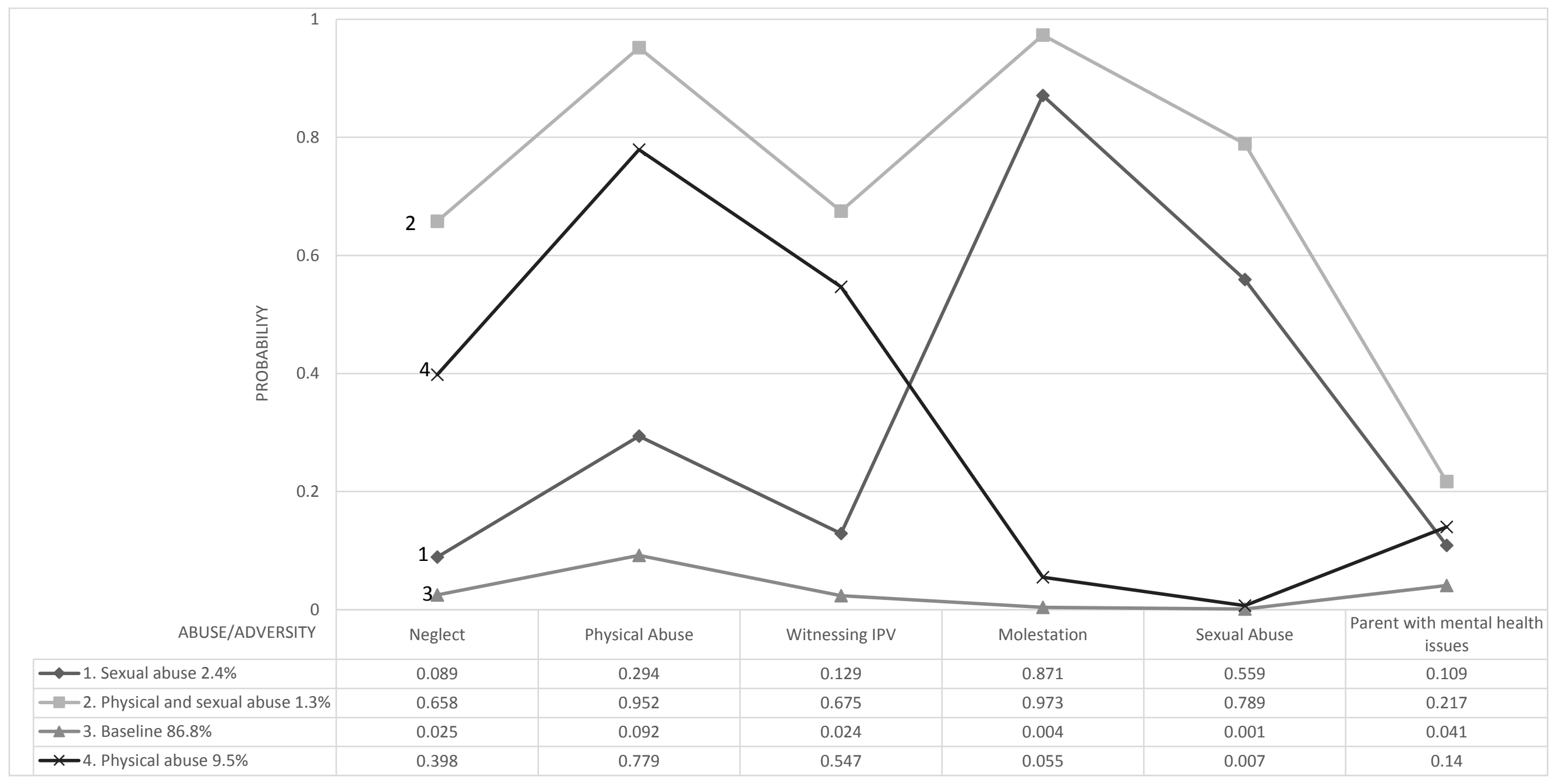

Figure 3 Profile Plot - Latent Class Analysis for The Total Data. 
Table 6 Odds Ratios (Confidence intervals) for Diagnosis of Anxiety, Depression and PTSD for Total Data, Males and Females by Class Membership

\begin{tabular}{|c|c|c|c|}
\hline & Anxiety & Depression & PTSD \\
\hline \multicolumn{4}{|l|}{ Males } \\
\hline Sexual Abuse & $6.033 *(3.89-9.34)$ & $5.786 *(4.01-8.34)$ & $6.972 *(4.65-10.46)$ \\
\hline Physical Abuse & $2.783 *(2.28-3.40)$ & $2.538 *(2.21-2.91)$ & $4.052 *(3.42-4.80)$ \\
\hline Sexual and Physical Abuse & - & - & - \\
\hline (Baseline) & - & - & - \\
\hline \multicolumn{4}{|l|}{ Females } \\
\hline Sexual Abuse & $2.893 *(2.44-3.42)$ & $3.250 *(2.84-3.72)$ & $4.697 *(4.05-5.44)$ \\
\hline Physical Abuse & $2.422 *(2.11-2.78)$ & $2.449 *(2.20-2.72)$ & $3.578 *(3.17-4.04)$ \\
\hline Sexual and Physical Abuse & $4.435^{*}(3.55-5.53)$ & $5.071 *(4.13-6.22)$ & $11.397 *(9.31-13.95)$ \\
\hline (Baseline) & - & - & - \\
\hline \multicolumn{4}{|l|}{ Total } \\
\hline Sexual Abuse & $3.468 *(2.97-4.05)$ & $3.810 *(3.37-4.30)$ & $5.423 *(1.20-1.86)$ \\
\hline Physical Abuse & $2.498 *(2.22-2.81)$ & $2.413 *(2.21-2.63)$ & $3.653 *(1.03-1.84)$ \\
\hline Sexual and Physical abuse & $5.223 *(4.29-6.36)$ & $5.824 *(4.87-6.96)$ & $12.823 *(10.75-15.31)$ \\
\hline (Baseline) & - & - & - \\
\hline
\end{tabular}

* Statistical significance $\mathrm{p}<.05 .95 \%$ confidence intervals in parenthesis. Reference group were low probability of all abuses/adversities 